clear that, following the usual procedure for the chromatographic technique, carotene undergoes change into another pigment when repeatedly adsorbed on alumina, even when oxygen is rigorously excluded.

In view of the widespread and successful use of chromatographic methods ${ }^{7}$ in the carotenoid field, it is important that the possibility should be recognised that changes can occasionally be brought about by the process itself.

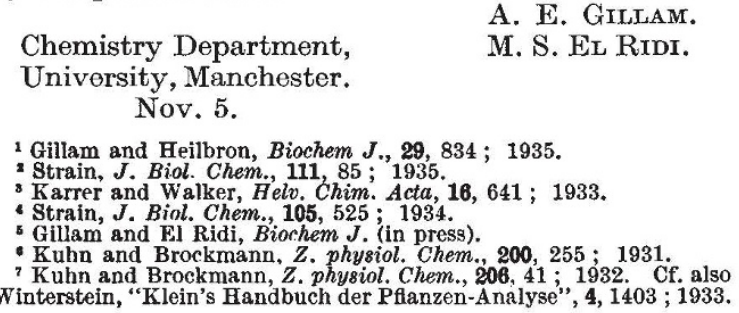

\section{Plasticity of Bismuth}

IN an earlier letter ${ }^{1}$ one of us (W. F. B.) tried to explain the discrepancies which exist concerning the plasticity of bismuth. It was confirmed that crystals obtained by different methods behave quite differently; for example, that soft crystals, that is, crystals which slip in tensile tests at room temperature, occur among those made in air (Czochralski method), whereas only hard crystals are obtained in vacuo (Bridgman method). Since the crystals made under atmospheric pressure were found to contain some gas, it was suggested that the gas was responsible for their softness. Hard crystals made in vacuo were found to slip in eompression tests at room temperature and in tensile tests at higher temperatures ${ }^{2}$. Experiments by Gough ${ }^{3}$ and by Andrade and Roscoe ${ }^{4}$ seem to support these findings.

Since the difference mentioned above is not the only one in making the crystals, it was desirable to apply a method which would allow the crystals to be grown in vacuo or under pressure while keeping all other factors constant. A method devised by Andrade and Roscoe ${ }^{4}$ has been found suitable for this purpose. In it a furnace travels horizontally along a wide glass tube, in which lies a thin piece of wire to be made into a single crystal. The glass tube can be evacuated or filled with gas. By this method it is easy to get crystals of any desired orientation by using a seed crystal.

The wires used were 1-2 $\mathrm{mm}$. in diameter and were obtained by casting in vacuo, to be sure that they were free of gas. The material was (1) that used in the earlier experiments, (2) Hilger's spectroscopically pure Bi No. 9506, the same material, we understand, as used by Andrade and Roscoes. Crystals were grown from (1) in vacuo, and in nitrogen, hydrogen, carbon dioxide ; from (2) in vacuo only. The rate of growth was $1.6 \mathrm{~mm}$. $/ \mathrm{min}$.

Under all conditions some of the crystals obtained were soft. So far as the experiments on crystals grown under atmospheric pressure are concerned, these results are a qualitative confirmation of those of Georgieff and Schmid ${ }^{6}$, since their erystals, obtained by the Czochralski method, contained gas. We consider the fact that crystals grown in vacuo show a similar behaviour, goes beyond their results, and it also seems at variance with the results of Andrade and Roscoe ${ }^{5}$. It remains to be seen whether the conformity of the crystals grown in gas and in vacuo is a quantitative one. We believe that the crystals made in vacuum exhibit the 'true behaviour' of bismuth, because the Andrade method seems the least objectionable of all. Any hard crystals found could be explained by unsuitable orientation ${ }^{6}$. Thus the gas content seems to have little influence, and another explanation has to be found to show why bismuth crystals grown by Bridgman's method are hard. Here the material is cast into glass tubes and remains there while solidifying. Owing to the wellknown anomalous behaviour of bismuth, it seems possible that it becomes subject to heavy stresses from the surrounding glass while cooling under such conditions. We have confirmed the fact, already stated by Gough and $\mathrm{Cox}^{7}$, that one seldom finds a bismuth crystal obtained by this method which does not show mechanical twinning. It thus appears likely that the hardness of such crystals is but another example of strain hardening.

W. F. BERG.

L. SANDLER.

Physical Laboratories,

University,

Manchester.

Oct. 17.

1 NATURE, 133, 831; 1934

NATURE, 134, 143 ; 1934 .

${ }^{3}$ Proc. International Conference on Physics, 2, 180; 1934

ibid., 2, 176.

ibid, 2,176 .

Z. Phys. 36, 759: 1926 .

' $J$. Inst. Metals, 48, 227 ; 1932.

Dr. Berg has invited me to comment in print upon an earlier version of the above letter. In view of the somewhat contradictory nature of the findings communicated in his last two letters on the subject, I think that any attempt to estimate how far he has gone beyond Georgieff and Schmid may well await his final results, which will, no doubt, be shortly published with due circumstance in one of the technical journals. I have been unsuccessful in a private attempt to make Dr. Berg understand what I consider to be the significance of our results on bismuth, and I do not think that it would be profitable to renew the attempt in public. The letter does, however, contain one fact, previously unknown to me, which I note with interest, namely, that Dr. Berg has found useful our technique for growing strain-free single crystals*, which we had the pleasure of demonstrating to him in detail when he paid a personal visit to our laboratory last year.

University College,

E. N. Da C. Andrade.

London, W.C.l.

* Unpublished, except for a three-line reference in "Proceedings of the International Conference on Physics", 1934, p. 173.

\section{Coalescence in Stages between Two Drops of a Liquid}

IN a letter in NATURE of August $3^{x}$, Ian W. Wark and Alwyn B. Cox record their observation that "Small drops directed obliquely on to the surface of tap water do not immediately coalesce with it", and they suggest that the reason for this lies in the contamination of the surface by a thin film of grease or dust.

So far as one can see from this short description, the phenomenon seems to be identical with, or similar 